Abstract 479 Table 2 Comparison with published haematological toxicity data for cancer chemoradiotherapy with IMRT/VMAT

\begin{tabular}{|l|l|l|l|l}
\hline Parameter & Reported \% & $\begin{array}{l}\text { Comparator } \\
\text { value }\end{array}$ & UCLH \% & P value \\
\hline Grade 3 or more neutropenia & $2.7-19.2^{\%}{ }^{3-12}$ & $10 \%$ & & \\
\hline $\begin{array}{l}\text { Grade } 2 \text { or more } \\
\text { thrombocytopenia }\end{array}$ & $2.7-11.2^{3-11}$ & $8 \%$ & $33.3 \%$ & 0.000 \\
\hline Grade 3 or more lymphopenia & $22.5 \%^{13}$ & $22.5 \%$ & $96.3 \%$ & 0.000 \\
\hline
\end{tabular}

radiation. Maximum haematological toxicity observed is given in table 1.

Two had received less than 5 cycles of cisplatin due to thrombocytopenia, while 2 others for non-haematological toxicity. 3 others have managed 5 cycles with G CSF support

Table 2 gives a comparison with published haematological toxicity data for cervical cancer IMRT/VMAT.

Grade 4 lymphopenia was significantly associated with having extended field radiotherapy $(\mathrm{p}=0.029)$ and Grade 3 or more thrombocytopenia with induction chemotherapy $(p=0.021)$. No associations could be elicited with stage $111 \mathrm{c}$ or higher disease, having lymph node boost or dose more than $50.4 \mathrm{~Gy}$.

Conclusion Significantly worse Thrombocytopenia and lymphopenia was seen compared to published data. However, there is heterogeneity in patient populations and treatments within existing studies with little data on the effects of extended field radiotherapy, lymphnode boosts or induction chemotherapy. We are therefore conducting a dosimetric analysis to investigate if bone marrow sparing VMAT could reduce the toxicity in this population of patients.

Disclosures None.

\section{INCIDENCE OF SEXUAL DYSFUNCTION AMONG CERVICAL CANCER PATIENTS IN A TERTIARY MEDICAL CENTER TREATED WITH CHEMORADIATION FROM JUNE TO DECEMBER 2019}

Thalia Tubungbanua, Helen Amorin. Vicente Sotto Memorial Medical Center; Obstetrics and Gynecology

\subsection{6/ijgc-2020-ESGO.39}

Introduction/Background Gynecologic cancers greatly affect a woman's sexuality, sexual functioning, intimate relationships, and sense of self. Twenty-three to seventy percent of cervical cancer survivors report problems with their sexual functioning. However, little is known about how sexual dysfunction affect their quality of life since many of them report psychosexual healthcare needs, but only one-third seek professional help. Evaluating their female sexual function will help identify the presence of sexual dysfunction among cervical cancer survivors, provide appropriate intervention and improve their quality of life.

Methodology The study used a prospective, cross-sectional survey design that employed a self-administered questionnaire using the Female Sexual Function Index (FSFI) to identify the presence of sexual dysfunction among cervical cancer patients in a tertiary medical center from June to December 2019. Descriptive statistics were reported to describe the distribution of patients in terms of the different numerical variables, whereas frequency and simple percentage were used to determine the distribution of respondents in terms of the different categorical variables.

Results Forty-two cervical cancer patients were assessed. The mean age of the studied population was 44.85. More than half was married (59.52\%), and majority was from Cebu City (66.78\%). Approximately 43\% (42.86\%) finished college and were mostly catholics (69.05\%). The mean age of diagnosis was 42.85 , with an average gravidity and parity of 1 . Most of the patients interviewed were diagnosed with stage $3 \mathrm{~B}$ cervical cancer (42.86\%). The mean overall Female Sexual Function Index (FSFI) score of the studied population was 6.59, which indicated that all of the patients studied had female sexual dysfunction.

Conclusion All the cervical cancer patients included in this study had female sexual dysfunction as evidenced by the low FSFI scores in each of the 6 dimensions and low overall FSFI score.

Disclosures None.

\section{LOCAL AND SYSTEMIC CHANGES ASSOCIATED WITH THE INNATE IMMUNE RESPONSE AND IMMUNOREGULATORY MECHANISMS RESPONSIBLE FOR THE ESTABLISHMENT AND PROGRESSION OF INVASIVE CERVICAL CARCINOMA}

${ }^{1}$ Olga Kurmyshkina, ${ }^{2}$ Pavel Kovchur, ${ }^{3}$ Tatyana Volkova. ${ }^{1}$ Petrozavodsk State University; Institute of Medicine; Department of Human and Animal Physiology, Pathophysiology, Histology; ${ }^{2}$ Petrozavodsk State University; Institute of Medicine; ${ }^{3}$ Petrozavodsk State University; Institute of High-Tech Biomedicine

\subsection{6/ijgc-2020-ESG0.40}

Introduction/Background The mechanisms of innate immune response and the immune checkpoint (IC) system-governed mechanisms are the two interconnected areas currently becoming the focus of world research in view of the prospects for therapeutic reactivation of antitumor immunity. This may be especially relevant to virus-associated cancers (as, for example, most cases of cervical cancer), which are known to develop as a result of persistent infection, long-term antigen exposure and are frequently characterized by chronically inflamed environment and local and/or systemic immunosuppression. Studying the immune changes that accompany the earliest stages of tumor progression may provide insight into the mechanisms driving the onset of metastasis; and, in this respect, systemic changes observed in peripheral blood (PB) may possibly reflect local dysfunctions at the tumor site. In case of cervical cancer, these assumptions need more extensive research evidence.

Methodology To characterize the changes in the local microenvironment, we compared the transcriptomes of the early invasive squamous cell cervical cancer and its precursor high-grade 